\title{
LOS MICROCIBERJUEGOS Y EL APRENDIZAJE DE LAS CIENCIAS SOCIALES: EL MUNDO JAVA
}

\section{(The microcybergames and the learning of the Social Sciences: The java world)}

\begin{tabular}{|c|c|c|}
\hline & por & \\
\hline$\underline{\text { Article record }}$ & \multirow{3}{*}{ Juan Carlos Raña (icrt@telefonica.net) } & $\underline{\text { Ficha del artículo }}$ \\
\hline About authors & & Sobre los autores \\
\hline HTML format & & Formato HTML \\
\hline
\end{tabular}

\begin{abstract}
The possibilities and didactic limitations of the computer games stand out. The utility of the microcybergames in the educative surrounings of Internet is put of relief. In Java, the designs of the microcybergames are studied, emphasizing the advantages of predesigned applet over the ones generated by some author created tools. A selection of flexible and gratuitous applet with possible didactic use is made. Examples of applications of these applets in proper contents of Social Sciences in the no university curricula are incorporated.
\end{abstract}

\section{Keywords}

Java; Internet; microcybergames; Applet; Social Sciences; Educational Games; Computer Games; Learning Activities.

Resumen
Se destacan las posibilidades y limitaciones didácticas de
los juegos de ordenador. Se pone de relieve la utilidad de
los microciberjuegos en el entorno educativo de Internet.
Se estudian los diseñados en java, resaltándose las venta-
jas de applets prediseñados sobre los generados por algu-
nas herramientas de autor. Se realiza una selección de
applets flexibles y gratuitos con posible utilización didác-
tica. Se incorporan ejemplos de aplicación de estos ap-
plets en contenidos propios de las Ciencias Sociales en los
currículos no universitarios.
Descriptores
Java; Internet; Microciberjuegos; Applet; Ciencias Socia-
les; Juegos Educativos; Juegos de Ordenador; Actividades
de Aprendizaje

juegos. Estos todavía se usan mayoritariamente off line, aunque cada vez más ocupan un espacio en la Red que se convierte así, en un lugar privilegiado para contactar con jugadores de cualquier parte del mundo, llegando a establecerse auténticas comunidades virtuales. Usados con o sin conexión, los videojuegos son uno de los principales objetos de ocio de la juventud actual y una de las 
entradas más directas a la cultura informática y de la simulación (Gros, 2002; Esnaola, 2003).

Además de los videojuegos, existen en Internet una gran cantidad de juegos de menor envergadura que pese a su simplicidad también son capaces de divertirnos, contando con la ventaja de hacerlo gratuitamente en la mayoría de las ocasiones. Muchos están expresamente diseñados para ser accesibles on line por lo que su tamaño no suele ser excesivamente grande, estando desarrollados sobre todo en java, javascript y flash. A todo este conjunto lo denominaremos microciberjuegos, término que por ser más descriptivo, es preferible al de minijuegos.

Estos programas al igual que sus hermanos mayores, los videojuegos, pueden tener posibilidades educativas que van desde la mejora de la coordinación oculomotora y la visión espacial hasta facilitar el desarrollo de estrategias más o menos complejas para la resolución de problemas (Oliver y Jacob, 2000; Licona y Carvalho, 2001; Gómez, 2001; Grup F9, 2003), habiendo sido utilizados con éxito en el ámbito de las Ciencias Sociales (Grup F9, 1998; Aguayos, 2003). Los juegos más apropiados para este área en educación secundaria son los de estrategia y simulación (Gros et al., 1997), géneros que por su complejidad técnica están más ligados al mundo de los videojuegos; aunque hay otros géneros, que suelen desarrollarse como microciberjuegos, que también pueden resultar útiles en primaria y secundaria para las facetas espacial, icónica, estética y verbal.

\section{¿QUÉ HACE QUE UN JUEGO SEA DIDÁCTICO?}

Las investigaciones de la pedagogía del juego han subrayado el valor formativo de los juegos (Tejedor, 2000). En cualquier tipo de juego se aprende algo, pero para que el juego sea realmente didáctico es necesario que ese "algo" tenga una importancia especial, unos objetivos y contenidos relevantes.
Para ello, el componente didáctico tiene que estar claramente definido, es necesaria una planificación-reflexión sobre los objetivos, contenidos y estrategias de aprendizaje adaptadas al momento evolutivo en que se encuentre el niño; eso sí, siempre sin perder de vista el componente lúdico pues de otro modo ya no estaríamos ante un juego.

Mediante los juegos se pueden aprender conceptos, estrategias cognitivas para la resolución de problemas, desarrollar la atención, la memoria, la fluidez verbal y numérica, el razonamiento, las capacidades creativas y de expresión gráfica o musical, etc. (García-Varcárcel, 1999; Albadalejo, 2001). Son instrumentos que pueden usarse en diferentes momentos del proceso de aprendizaje: previamente como elemento motivador, simultáneamente al desarrollo de los contenidos como complemento, o posteriormente en forma de refuerzo o profundización. Siempre habrá que adecuar el juego a la edad y necesidades del niño en función de los objetivos que se quieran conseguir.

\section{¿QUÉ VENTAJAS TIENEN LOS MICROCIBERJUEGOS?}

Las ventajas de los juegos de ordenador ya fueron puestas de manifiesto por Ana García-Valcárcel (1999). Al igual que en la pantalla de televisión cualquier movimiento en el monitor del ordenador hace que le prestemos atención, aún de forma involuntaria. Además, su carácter interactivo exige una continua actividad mental y motórica que dificulta la pérdida de atención. Rapidez y velocidad en las partidas, variedad de acciones y movimientos, facilidad en el control del juego, son elementos muy valorados por los jugadores. En tercer lugar, su capacidad multimedia posibilita que llegue de forma muy diversa, no sólo a nuestros ojos, sino también al oído y en un futuro no muy lejano al tacto y el olfato. La calidad de los gráficos, imágenes y localizaciones, animaciones realistas, efectos especiales son elementos clave en la aceptación de los juegos. El orde- 
nador por su capacidad de soportar información compleja e interactiva es ideal para su desarrollo.

Los microciberjuegos participan en mayor o menor medida de estas características, con la ventaja añadida de ser fácilmente asequibles tanto para el desarrollador como para el usuario. Respecto a su elaboración, no necesitan equipos de decenas de personas como algunos videojuegos, pues sus pretensiones son menores y además existen herramientas de autor y módulos que pueden ser empleados para su desarrollo sin excesivos conocimientos de informática. Esto los pone al alcance de los profesionales de la educación, más aún cuando el empleo de algunas de estas herramientas y módulos bajo determinadas condiciones es gratuito. Así, los profesores podrán desarrollar actividades didácticas en los que el componente lúdico esté más o meno acentuado. Desde el punto de vista del alumno el acceso a estas actividades es muy fácil, debido al pequeño tamaño que facilita su descarga y almacenamiento.

\section{LIMITACIONES}

Entre los peligros que afectan a los videojuegos se ha destacado (Oliver y Jacob, 2000; Figueras; 2000) que pueden causar adición, conducta asocial, incluso lesiones articulares. Respecto a los contenidos, se plantea el problema de que en los ciberjuegos se transgreden las normas físicas y sociales sin sufrir consecuencias de ningún tipo, lo cual puede llevar a minusvalorar determinadas acciones en el mundo real. Esto es especialmente grave cuando los contenidos de los juegos son del todo rechazables por sexistas, racistas o extremadamente violentos. Por ahora, esta limitación respecto a los contenidos no afecta excesivamente a los microciberjuegos dado su escaso nivel de desarrollo en comparación con los videojuegos, aunque comienza a ser preocupante el contenido de determinados "chistes fáciles" multimedia y las invitaciones a juegos de azar.
Una limitación más importante es que sustituyen la experiencia real por experiencias virtuales, lo cual es positivo en tanto nos permite llegar a ellas, pero no es aceptable si sustituyen completamente la realidad cuando esta es accesible, por eso el tiempo de juego con el ordenador no debe sobrepasar más de una hora u hora y media diaria, son necesarias otras interacciones con el mundo real, en especial las sociales. Buena parte del buen empleo de los juegos dependerá que la dificultad y contenido se adapten a las necesidades y edad del usuario.

Mayor limitación es que los juegos de ordenador, pueden favorecer aprendizajes mecánicos, por ensayo-error, o aprendizajes excesivamente simples, no siendo actualmente el instrumento más adecuado para el desarrollo de procesos cognitivos más elevados.

Padres y profesores deben ser conscientes de estas limitaciones, que pueden convertirse en algún caso en auténticos peligros; aunque también, deben saber que los ciberjuegos pueden ser un complemento agradable para el desarrollo de contenidos.

\section{¿CÓMO DESARROLLAR MICRO- CIBERJUEGOS DE INTERÉS EDU- CATIVO?}

He realizado una selección de microciberjuegos de interés educativo, que lógicamente no es exhaustiva como demuestran los miles de ejemplos que ofrece cualquier directorio o buscador. En esta entrega me limito al lenguaje Java, que permite el desarrollo de aplicaciones más potentes que Macromedia Flash, Macromedia Shockwave, Javascript o DHTML, pero también más pesadas al consumir más recursos.

Java ${ }^{[i]}$ es un lenguaje de programación orientado a objetos, desarrollado por Sun Microsystems ${ }^{[i i]}$, a través del cual es posible escribir applets, esto es, programas en java que se ejecutan en cualquier ordenador siempre que el navegador lo soporte. Este es el 
el caso de los navegadores más populares en el mercado, pese a que la política comercial de Microsoft decidiera no incorporarlo inicialmente en Windows XP y fuera necesario descargar un programa de gran tamaño para que Internet Explorer pudiera ejecutar estos applets.

La programación de un applet no es difícil pero resulta una tarea inasequible para el profano, por lo que existen en el mercado programas y herramientas de autor que los generan con cierta facilidad. Entre ellas destacamos dos ligadas al mundo java. Por un lado, Quia ${ }^{[\text {iii] }}$ con la que se pueden crear catorce tipos de juegos y actividades educativas, la mayoría en java, aunque tiene el inconveniente de no ser un programa gratuito. Las actividades creadas con Quia-web son generadas directamente en el servidor de la compañía.

Por el contrario, la segunda herramienta sí es gratuita. Se trata del programa español Clic ${ }^{[i v]}$ desarrollado por la Consejería de Cultura y Educación de la Generalitat catalana. Se ha traducido a varias lenguas, siendo el programa más utilizado en educación primaria en Cataluña. (Bosco, 2002). Originariamente no estaba orientado a la Red, pero el proyecto $\mathrm{JClic}{ }^{[\mathrm{v}]}$ que lo sustituirá pretende desarrollar el programa JClic autor, que permitirá la creación de estas actividades para Internet accesibles mediante un applet que ya está disponible: JClic applet. Respecto a éste último, aún en fase beta, tiene el inconveniente de no funcionar en la máquina virtual de java de Microsoft por lo que obliga al usuario a instalar una versión actualizada de motor Java ${ }^{\mathrm{TM}} 1.3 .1$ (ocupa algo más de 8 $\mathrm{Mb}$ ), prepararlo para reconocer la firma digital de JClic (ocupa algo más de 500 bytes) y añadir el módulo Java Media Framework para sonidos MP3 y secuencias de vídeo digital (cerca de $2 \mathrm{Mb}$ ). En sistemas Windows la instalación de estos elementos se realiza mediante un programa que se puede descargar de la página de JClic, que ocupa cerca de $11 \mathrm{Mb}$ y que no siempre se instala sin pro- blemas. Todas estas son demasiadas acciones previas para un usuario novel, pero el mayor inconveniente es el excesivo tamaño del plug-in que hay que añadir. Cabe esperar que esto se resuelva en el futuro ya que en su concepción es un buen programa por lo que esperamos que esta nueva versión de Clic pueda convertirse en un punto de referencia para actividades generadas para Internet, al igual que lo es en otros ámbitos. No obstante, hay que considerar que la progresiva ex-

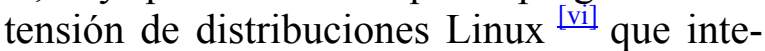
gran el motor Java de Sun podrían paliar estos problemas, pero hoy por hoy, sigue siendo un sistema operativo difícil de configurar para los no iniciados.

Una alternativa a estos programas es la elaboración de las actividades didácticas mediante applets ya elaborados, pues, aunque no siempre tienen un propósito educativo, se pueden reprogramar para que lo tengan. Su tamaño es decenas e incluso centenares de veces inferior al plug-in de JClic posibilitando una navegación extremadamente más veloz, que en el caso de los accesos a través de módems significa la única con posibilidades reales. Además de esta característica he seleccionado sólo aquellos cuyo uso no comercial es gratuito. También he tenido en cuenta alcanzar un equilibrio entre la potencia y la facilidad de uso, en especial en el ámbito hispanohablante, pues no todos los applets que hay en la Red permiten modificar sus parámetros para ser usados en otra actividad distinta a la que fueron concebidos. Ciertamente son productos más rígidos que JClic pero su carácter modular y la gran variedad existente en la Red contrarrestan este inconveniente. Por otro lado, la potencia es igual y a veces superior a los resultados obtenidos con herramientas de autor, incrementándose en el caso de que paguemos por algunas actualizaciones. Estos applets son programas freeware o shareware, que se ofrecen de forma gratuita plenamente operativos o bajo alguna restricción, siempre que se cumplan algunas condiciones; las cuales, podremos encontrar en la dirección de correo 
Raña, J.C. (2003). Los microciberjuegos y el aprendizaje de la ciencias sociales: el mundo Java. RELIEVE, v. 9 , n. 2, p. 236-246. http://www.uv.es/RELIEVE/v9n2/RELIEVEv9n2_6.htm

o en la página web de sus autores. La segunda gran ventaja de estos applets es que no exigen ninguna acción especial por parte del alumno que se limita a interactuar con la actividad. $\mathrm{Y}$ en tercer lugar, los profesores que quieran desarrollar juegos didácticos, pueden hacerlo con tan sólo unos conocimientos básicos de informática.

\section{EJEMPLOS DE JUEGOS BASADOS EN APPLETS APLICADOS AL ÁM- BITO DE LAS CC. SS.}

Existen en Internet muchos lugares que ofrecen gratuitamente applets reprogramables, por ejemplo Usina Quiz ${ }^{[\mathrm{rii}]}$ o Word Games and Variety Puzzles [viii]. En este artículo presento una selección de diecinueve applets y veinte ejemplos aplicados a contenidos propios de las Ciencias Sociales en los currículos no universitarios; aunque pueden resultar también útiles en otras áreas, especialmente para los idiomas y la educación plástica y visual. He añadido los ejemplos porque frecuentemente se tratan estos temas sólo en forma teórica y es bueno poder comparar también resultados prácticos. Sólo presento ejemplos elementales de microciberjuegos para ver cómo pueden ser implementados, por lo que no se pretenda encontrar actividades de aprendizaje elaboradas y complejas, pues los applets no serían más que módulos en ellas.

La muestra seleccionada se clasifica en tres grupos: juegos de imagen, juegos de texto, juegos de preguntas y de asociación.

\section{Juegos basados en la imagen.}

Este tipo de juegos se encuentra dentro de la categoría de los llamados juegos constructivos. Suponen la posesión de destrezas sensitivas y motrices, así como el aumento de la capacidad de utilización de los procesos intelectuales implicados en el reconocimiento y el recuerdo de elementos memorizados con anterioridad. Contienen tres subgrupos:

\section{1. a) Juegos para dibujar, componer y co- lorear.}

Se trata de juegos creativos que favorecen el desarrollo de la imaginación, a veces también instructivos si se asocian personajes o lugares con los que familiarizarse. Están indicados para todos los niveles, pero especialmente para los más pequeños. Este tipo de actividades no está presente en Quia y en Clic.

\section{1.a. 1) Juegos para dibujar.}

- ADraw v.1.0, es un applet de R. Bertheou que se puede encontrar en JavaSide.com ${ }^{[i x]}$. Permite dibujar sin que el alumno tenga instalado en su ordenador ningún programa específico para ello, e incluso guardar estos dibujos en formato gif y png, previa generación de los archivos en un servidor mediante los componentes jspImage o acxImage. El ejemplo Mi pizarra I lo he reprogramado con una configuración básica sin que se pueda guardar la imagen pero sí imprimirla.

- Anfypaint, permite el desarrollo y envío de los dibujos realizados a través de ftp y correo electrónico. Es una creación de Fabio Ciucci y lo podemos encontrar dentro del paquete Anfy $2.0^{[\mathrm{x}]}$ Es un applet más potente pero shareware, por lo que tiene el inconveniente de que al utilizarlo presenta una molesta ventana invitándonos a registrarlo, aunque para hacerla desaparecer bastará con minimizarla. En el ejemplo Mi pizarra II propongo en una configuración básica sin la opción de envío por correo o FTP, aunque sí será posible imprimir el resultado.

\section{1.a. 2) Juegos para componer escenas y figuras.}

- Mr. Potato, de Gunn Steve White ${ }^{[x i]}$, permite componer escenas y figuras a partir de la combinación de sus elementos. Es un applet pensado para los más pequeños. No añado ejemplo, pues recomiendo los que incluye la página de origen, especialmente los de la charca y la granja. 


\section{1.a. 3) Juegos para colorear imágenes.}

ColoringBook, es un applet de Eric Harshbarger ${ }^{[x i i]}$, que permite colorear cualquier imagen. Veamos tres ejemplos: Colorea monumentos del mundo, Colorea personajes de la Historia de España $y$ Colorea personajes de los siglos XIX Y XX.

\section{1. b) Juegos de rompecabezas.}

Son juegos que desarrollan la observación, la concentración, la memoria visual, además de ser útiles para la instrucción icónica. Se trata de una imagen original que se fragmenta en un conjunto de piezas que hay que recomponer. Contienen tres subtipos:

\section{1.b. 1) Rompecabezas de piezas conmuta- bles.}

-JSawPuzzle es un applet de Wouter Wijtenburg ${ }^{[x i i i]}$. En este puzzle hay que intercambiar las piezas hasta lograr la recomposición de la imagen. Rompecabezas de este tipo también se pueden crear con Clic. En el ejemplo Los romanos, parto de una imagen del Coliseo.

\section{1.b. 2) Rompecabezas de piezas desliza- bles.}

En este tipo de juego la reconstrucción se consigue desplazando las piezas al lugar adyacente hasta obtener la imagen. Recojo dos variantes:

- SlidePuzzle, de Paul Koerber $\stackrel{\lfloor x i v \mid}{ }$, en el que el fragmento desplazable sólo puede ser aquel que sea adyacente a un hueco que se deja entre el conjunto de la imagen fragmentada. Este tipo de juego, también es posible realizarlo con Clic. El ejemplo que muestro, está basado en Las cariátides del Erecteion e incorpora información del tiempo empleado y los movimientos realizados.

OmniSlide, programa del que es autor Donald Sapello ${ }^{\lfloor x v \mid}$, prescinde de la existencia de un hueco para poder desplazar las piezas, empujando a todas las demás en una dirección. No es posible desarrollarlo con Clic. En el ejemplo Arquitectura del mundo, me baso en tres imágenes de conocidos monumentos que permiten apreciar la posibilidad del applet para cargarlas indistintamente a voluntad del usuario, así como para cambiar su grado de fragmentación.

\section{1.b. 3) Rompecabezas de reconstrucción pieza a pieza.}

- Jigsaw , del que también es responsable Steve White, permite realizar puzzles en los que para recomponer la imagen es necesario colocar pieza a pieza los fragmentos desde cualquier sitio en que se encuentren. Este tipo de juego se puede realizar también con Clic. El applet de Steve White, genera contornos irregulares que obligan a que las piezas casen no sólo por la lógica de la imagen sino también por su forma, además es posible que las piezas se encuentren giradas hasta $270^{\circ}$ e incluir una imagen guía de fondo. En este caso, el ejemplo parte de una obra pictórica muy conocida: La rendición de Breda.

\section{1. c) Juegos de memoria.}

Como su nombre indica, tratan de desarrollar la memoria, en especial a corto plazo, además de la capacidad de concentración. El más típico es el que tiene por objetivo descubrir dos imágenes iguales en dos pulsaciones consecutivas, escondiéndose las piezas en caso contrario. No se trata de actividades asociativas complejas, pues las parejas son idénticas, aunque si colocáramos vocablos o imágenes relacionados, sí estaríamos ante una actividad de este tipo, con la dificultad añadida de que las imágenes no se mantienen en pantalla.El applet seleccionado es:

Concentration, igualmente obra de Eric Harshbarger. Este tipo de juegos también es posible realizarlos con Clic. En este caso el ejemplo, se centra en la Arqueología de la Antigüedad, incorporando piezas relevantes de esta etapa, cuya resolución mostrará una conocida imagen de la época. 
Raña, J.C. (2003). Los microciberjuegos y el aprendizaje de la ciencias sociales: el mundo Java. RELIEVE, v. 9 , n. 2, p. 236-246. http://www.uv.es/RELIEVE/v9n2/RELIEVEv9n2_6.htm

\section{Juegos basados en texto.}

Son juegos adecuados para el desarrollo de conceptos verbales. Familiarizan al alumno con cierto vocabulario o refuerzan el aprendizaje del mismo. Normalmente se trata de descubrir palabras o frases escondidas. Veamos cuatro subtipos:

\section{2. a) Sopa de letras.}

Tiene como fin encontrar palabras escondidas en una parrilla de letras. Esta actividad puede realizarse con Clic, que incluye una mejora muy importante que por ahora no he encontrado en ningún applet: la capacidad de proporcionar un feedback por cada palabra descubierta. Selecciono dos applets:

- Word Search, de Mike Hall ${ }^{[\mathrm{xvi}]}$. Permite incorporar varios juegos de preguntas así como mostrar la solución de todas las palabras de un juego. El ejemplo lo he desarrollado sobre vocabulario del siglo XVIII, recogiendo dos juegos de preguntas, uno sobre Europa y otro sobre España, para mostrar como el applet permite su carga consecutiva sin variar de pantalla.

- Seek-A-Word, de Eric Harshbarger, incorpora sonido y permite buscar una a una las palabras que se nos resistan. En este caso he añadido un ejemplo sobre la Grecia Antigua , al que he dado un fin más didáctico al sugerir la búsqueda del significado del vocabulario que se encuentra en el juego.

\section{2. b) Letras entremezcladas.}

Aquí, no son palabras enteras las que están escondidas sino las letras que forman una palabra. Se trata de reordenarlas hasta descubrir la palabra. He seleccionado el applet:

- Jumble, de Eric Harshbarger. En el ejemplo muestro una lista de palabras que tienen que ser descubiertas; todas ellas tratan sobre El sexenio democrático en España.

\section{2. c) El ahorcado.}

El juego consiste en ir descubriendo las letras que forman una palabra o expresión a partir del conocimiento del número de letras que la componen. En el juego clásico, por cada letra que no se acierta se dibuja una parte de un monigote ahorcado, perdiendo el jugador cuando el número de intentos erróneos es tan grande que el dibujo se completa. En el caso de que incorporara una pregunta que sirviera de pista para descubrir las palabras ocultas, se convertiría en un juego más complejo que habría que insertar en el tercero de los grandes grupos establecidos en este artículo. El applet seleccionado:

Bones, obra de Mc Kendrick, ${ }^{[\mathrm{xviii}]}$ tiene la ventaja de ser menos drástico y en lugar de mostrar un ahorcado y el patíbulo, cada error irá disminuyendo el número de huesos con los que un perrito está soñando. Sin embargo, tiene el inconveniente de no ofrecer frases que sirvan de pista para descubrir las palabras ocultas, lo cual lo convierte en un juego elemental de completar huecos. El ejemplo que he realizado trata sobre $\underline{E l} \mathbf{r o}$ manticismo, y se acompaña también de sonido.

\section{2. d) Descubrir frases.}

En este caso, se descubren frases en las que hay palabras a las que falta alguna letra. Es el típico juego de completar los huecos. Se han seleccionado dos applets de Remelar D.P. ${ }^{[\mathrm{xvii}] \text { : }}$

- Missing Vowels Quote, con el que propongo un ejemplo sobre el concepto de Democracia.

- Anagram Quote, con el que realizo un ejemplo sobre el Principio de legalidad en la Constitución de 1978.

\section{Juegos de preguntas y de asociación.}

Forman este grupo los juegos basados en textos o en imágenes con un mayor nivel de 
complejidad que los que integran los dos grupos anteriores.

\section{3. a) Juegos de asociación.}

Su objetivo es la asociación de parejas de conceptos expresados por palabras, frases o imágenes. Los integrantes de estas parejas, no son idénticos y se ofrecen por completo al jugador, que sólo tiene que descubrir cuáles son los que están asociados. El applet seleccionado es:

- MatchingPhrases de Armin Steinicke. ${ }^{[x x i i]}$ Permite la asociación de frases. Como ejemplo acompaño un juego sobre $\underline{L} \boldsymbol{a}$ religión griega.

\section{3. b) Preguntas con respuesta de elección múltiple.}

Es el típico test convencional, en el que se van ofreciendo preguntas con varias respuestas entre las que hay que identificar la verdadera. El applet seleccionado, por su originalidad, es:

- Photoquizz, del que es responsable Christophe Caissotti. ${ }^{[\mathrm{xx}]} \mathrm{El}$ ejemplo que he reprogramado es Descubre el personaje, centrándose en la biografía como técnica historiográfica.

\section{3. c) Los crucigramas.}

En este juego se deben descubrir palabras que se entrecruzan, a partir de definiciones o sugerencias y de las pistas que van generándose con el conocimiento de las letras de otras palabras que hayamos acertado. El applet que se acompaña es:

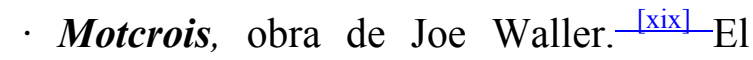
ejemplo trata sobre La prehistoria.

\section{3. d) Juegos de preguntas y respuestas que deben ser completadas.}

Se trata de test que tienen la dificultad añadida de que no es suficiente identificar la respuesta correcta, sino que ésta se debe rememorar. El applet que presento es:
- chrono, del que es autor J-Hazeltine. ${ }^{[\mathrm{xxi}]}$ El ejemplo, Continentes y ríos, desarrolla una actividad geográfica elemental.

\section{CONCLUSIONES}

Tras examinar estos ejemplos podemos concluir que los microciberjuegos por su facilidad de acceso, precio e interactividad, son programas ideales para ser usados como pasatiempos y aprovechados didácticamente, con todas las limitaciones que les son propias. El límite entre el juego y la actividad didáctica no siempre es nítido, de hecho hay pasatiempos basados en preguntas que si bien favorecen una cultura que despectivamente se califica "tipo Trivial", no deja de ser cultura y desde luego más deseable que otros tipos de actividades también calificadas de lúdicas.

Más allá del juego, en el ámbito más específicamente educativo, la modularidad de los applets permite integrarlos dentro de auténticas actividades formativas, especialmente en el proceso de aprendizaje del vocabulario verbal e icónico, como por ejemplo he propuesto al usar Seek-A-Word. A partir de aquí, junto con lecturas y explicaciones complementarias, el alumnado debería identificar y utilizar este vocabulario en otras actividades más complejas que se le propongan. Actividades semejantes se han elaborado usando flash o javascript para atender a la diversidad ${ }^{[x x i i i]}$, o para la autoevaluación formativa (Raña, 2002, 2003).

Por ahora, los microciberjuegos no cubren más que ciertas estrategias de aprendizaje simples que pueden complementar el desarrollo de procesos mentales más complejos accesibles mediante otros instrumentos y estrategias de aprendizaje. En el futuro, aunque java pueda evolucionar, seguirán programándose nuevos applets, muchos de los cuales estarán disponibles gratuitamente en Internet y posibilitarán actividades más com- 
Raña, J.C. (2003). Los microciberjuegos y el aprendizaje de la ciencias sociales: el mundo Java. RELIEVE, v. 9, n. 2, p. 236-246. http://www.uv.es/RELIEVE/v9n2/RELIEVEv9n2_6.htm

plejas, especialmente en el mundo de la simulación.

A pesar de las reticencias de Microsoft en el soporte de este lenguaje, nuevos proyectos asociados al mundo Linux, particularmente Linex, ${ }^{[\mathrm{xxiv}]}$ desarrollado por la Junta de Extremadura y Guadalinex $\stackrel{[x x v]}{ }$, de la Junta de Andalucía, son un campo abonado para su extensión ya que java es un lenguaje multiplataforma; de manera que los applets gratuitos podrán ser usados sin ningún problema en un sistema operativo también gratuito. Más recientemente, la implementación de tecnología java en la telefonía móvil, que hace las delicias de nuestros jóvenes, nos descubre una nueva área de aplicación de un potencial didáctico que no debe ser despreciado.

\section{BIBLIOGRAFÍA}

Aguayos, J. (2003). Videojocs $i$ ensenyament. Consultado el 10 octubre 2003 en http://www.xtec.es/ jaguayos/.

Albadalejo Nicolás, Juan José (2001). El juguete didáctico: una herramienta para su evaluación, Píxel-bit, n. 16. Consultado en http://www.sav.us.es/pixelbit/articulos/n16/ n16art/art169.htm el 10 noviembre 2002.

Balaguer, Roberto (2002). Videojuegos, Internet, Infancia y Adolescencia del nuevo milenio, Kairos, año 6 n. 10, $2^{\circ}$ semestre 2002.Consultado el 15 enero 2003 en www.fices.unsl.edu.ar/kairos/k10-06.htm .

Bosco, Alejandra (2002). Sobre el Clic y su éxito en la educación escolar, Bits Espiral. Consultado el 3 octubre 2003 en www.ciberespiral.org/bits/Clic.pdf.

Esnaola, Graciela (2003). Reflexiones psicopedagógicas en torno a la digitalización del espacio lúdico, en.red.ando, num 357, 4Febrero. Consultado en http://enredando.com/cas/cgi-

bin/enredantes/plantilla.pl?ident $=249$ el 12 octubre 2003.

Figueras Maz, Mónica (2000). El ocio como realidad educativa. La experiencia de la Fundació Pere Tarrés, $6^{\circ}$ Congreso Mundial de Ocio. Ocio y Desarrollo Humano. Bilbao 3-7 de julio de 2000. Universidad de Deusto. Consultado en http://www.ocio.deusto.es/formacion/ocio2 1/pdf/P03109.pdf el 15 enero 2003.

García-Valcárcel Muñoz-Repiso, Ana (1999). El juego y las nuevas tecnologías, Píxel-bit, n. 13. Consultado en http://www.sav.us.es/pixelbit/articulos/n13/ n13art/art137.htm el 10 noviembre 2002.

Gil Larrea, María José; González Barturen, Jorge; Vázquez Gómez, Iñaki (2000). Ocio ¿a través de Internet?, $6^{\circ}$ Congreso Mundial de Ocio. Ocio y Desarrollo Humano. Bilbao 3-7 de julio de 2000. Universidad de Deusto. Consultado en http://www.ocio.deusto.es/formacion/ocio2 1/pdf/P07269.pdf el 15 enero 2003.

Gómez Cañete, Daniel (2001). Juegos para aprender, en en.red.ando, n. 298, 18-122001.

Consultado en

http://enredando.com/cas/cgibin/juegos/plantilla opi.pl?ident $=98$ el 9 octubre 2003.

Gros Salvat, Begoña et al. (1997). La utilización de los juegos de ordenador en la escuela, III Congreso Eductec. Creación de Materiales para la Innovación Educativa con Nuevas Tecnologías. Málaga 27 a 29 de octubre de 1997. Universidad de Málaga. Consultado el 19 septiembre 2001 en www.ieev.uma.es/edutec97/edu97 c5/2-509.htm.

Gros Salvat, Begoña (2002). Videojuegos y alfabetización digital, en.red.ando, num. 160, 7-5-2002. Consultado en. http://enredando.com/cas/cgibin/enredantes/plantilla.pl?ident $=227$ el 12 octubre 2003.

Grup F9 (1998). Ciencias Sociales y juegos de ordenador: jugando con Carmen Sandiego, Cuadernos de Pedagogía. 289, 24-27. Consultado el 10 octubre 2003 en www.xtec.es/ abernat/altres $\% 20$ articles/soc iales.pdf.

Grup F9 (2002). Diseñar información en un mundo complejo. Informe interno del grupo de trabajo. Universitat Autònoma de Barcelona. Julio. Consultado en 
Raña, J.C. (2003). Los microciberjuegos y el aprendizaje de la ciencias sociales: el mundo Java. RELIEVE, v. 9 , n. 2, p. 236-246. http://www.uv.es/RELIEVE/v9n2/RELIEVEv9n2 6.htm

http://www.xtec.es/ abernat/altres\%20articl es/disenar.pdf el 10 octubre 2003)

Licona Vega, Ana Liliam y Carvalho Levy, Denize Piccolotto (2001). Los videojuegos en el contexto de las nuevas tecnologías: relación entre las actividades lúdicas actuales, la conducta y el aprendizaje, Píxel-bit, n. $\quad 17 . \quad$ Consultado en http://www.sav.us.es/pixelbit/articulos/n17/ n17art/art174.htm el 11 noviembre 2002.

Oliver, Javier y Jacob, Inés (2000). ¿Es perjudicial que los jóvenes utilicen videojuegos?, $6^{\circ}$ Congreso Mundial de Ocio. Ocio y Desarrollo Humano. Bilbao 3-7 de julio. Universidad de Deusto. Consultado en http://www.ocio.deusto.es/formacion/ocio2 1/pdf/P06270.pdf el 15 enero 2003.

Raña Trabado, Juan Carlos (2003). Autoevaluación formativa informatizada en las CC. SS., Quaderns Digitals.NET, no 29. Consultado

http://www.quadernsdigitals.net/apli/qd.php ?accionMe-

$\underline{\mathrm{nu}=\text { hemeroteca. } \text { VisualizaArticuloIU.visuali }}$ za\&articulo $\mathrm{id}=5909$. el 5 marzo 2003.

Raña Trabado, Juan Carlos (2002). Hot Potatoes y las Ciencias Sociales, A pie de aula. Consultado

en

http://www.gh.profes.net/archivo2.asp?id c ontenido=32905 el 10 septiembre 2002.

Tejedor Mardomingo, María. La calidad del ocio educativo, $6^{\circ}$ Congreso Mundial de Ocio. Ocio y Desarrollo Humano. Bilbao 37 de julio de 2000. Universidad de Deusto. Consultado en http://www.ocio.deusto.es/formacion/ocio2 1/pdf/P03216.pdf el 16 enero 2003. [i] The Source for JavaTM Technology http://java.sun.com

${ }^{[i i]}$ Sun Microsystems http://www.sun.com/

${ }^{[i i i]}$ Quia http://www.quia.com/

${ }^{[i v]}$ The Clic corner http://www.xtec.es/recursos/clic [v]

http://www.xtec.es/recursos/clic/jclic/index_esp.htm

[vi] http://www.linux.org/

${ }^{\text {[vii] }}$ http://www.usinaquiz.ovh.org/

[viii]

http://www.stormpages.com/mypuzzle/mypuzzle/e.htm $\underline{1}$

${ }^{[i x]} \mathrm{http}: / /$ www.javaside.com

${ }^{[\mathrm{x}]} \mathrm{http}: / /$ www.anfyteam.com

${ }^{[\mathrm{xi}]} \mathrm{http}: / /$ svwhite.com/games

${ }^{[\mathrm{xii}]} \mathrm{http}: / /$ www.ericharshbarger.org

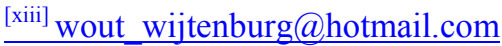

${ }^{[\mathrm{xiv}]}$ paul.koerber@rug.ac.be

${ }^{[\mathrm{xv}]} \mathrm{http}: / / \mathrm{www} \cdot$ sapello.com/slidepuzzle

${ }^{[\mathrm{xvi}]}$ http://www.brainjar.com/

[xvii]

http://www.stormpages.com/mypuzzle/mypuzzle/e.htm $\underline{1}$

${ }^{\left[{ }^{\text {xviii] }} \text { http://www.tehihard.com/ }\right.}$

${ }^{[\mathrm{xix}]}$ JoeWaller@orst.edu

[xx]java@,arcadevillage.com

[xxi] berdel@guetali.fr

[xxii] armstein@cs.tu-berlin.de

[xxiii]

http://www.educarm.es/materiales_diversidad/start.h

tm

${ }^{[\mathrm{xxiv}]} \mathrm{http}: / / \mathrm{www}$.linex.org/

${ }^{[\mathrm{xxv}]} \mathrm{http}: / /$ www.guadalinex.org/

\section{NOTAS}

\section{$\underline{\text { ABOUT THE AUTHORS / SOBRE LOS AUTORES }}$}

Juan Carlos Raña Trabado (jcrt@telefonica.net). Profesor de Geografía e Historia en el Instituto de Educación Secundaria No 1 "Universidad Laboral" de Málaga, cuya dirección es c/ Julio Verne, 6. 29080 Málaga. Su principal línea de trabajo es Internet y la enseñanza de las CC. SS. Posee experiencia en la formación permanente del profesorado, así como en el ámbito de la atención a la diversidad y la organización escolar. 
Raña, J.C. (2003). Los microciberjuegos y el aprendizaje de la ciencias sociales: el mundo Java. RELIEVE, v. 9 , n. 2, p. 236-246. http://www.uv.es/RELIEVE/v9n2/RELIEVEv9n2 6.htm

\section{ARTICLE RECORD / FICHA DEL ARTÍCULO}

\begin{tabular}{|c|c|}
\hline $\begin{array}{l}\text { Reference / } \\
\text { Referencia }\end{array}$ & $\begin{array}{l}\text { Raña, Juan Carlos (2003). Los microciberjuegos y el aprendizaje de las Ciencias Sociales: el } \\
\text { mundo java. Revista ELectrónica de Investigación v EValuación Educativa, v. 9, n. } 2 . \\
\text { http://www.uv.es/RELIEVE/v9n2/RELIEVEv9n2 6.htm. Consultado en (poner fecha). }\end{array}$ \\
\hline Title / Título & $\begin{array}{l}\text { Los microciberjuegos y el aprendizaje de las Ciencias Sociales: el mundo java [The microcy- } \\
\text { bergames and the learning of the Social Sciences: The java world ] }\end{array}$ \\
\hline $\begin{array}{l}\text { Authors / Auto- } \\
\text { res }\end{array}$ & 2 \\
\hline $\begin{array}{l}\text { Review / } \\
\text { Revista }\end{array}$ & Revista ELectrónica de Investigación y EValuación Educativa (RELIEVE), v. 9, n. 2 \\
\hline ISSN & $1134-4032$ \\
\hline $\begin{array}{l}\text { Publication date } \\
\text { / Fecha de publi- } \\
\text { cación }\end{array}$ & $\begin{array}{l}2003 \text { (Reception Date: } 2003 \text { March 11; Approval Date: } 2003 \text { Oct. 15; Publication Date: } \\
2003 \text { Oct. 17) }\end{array}$ \\
\hline \multirow{2}{*}{$\begin{array}{l}\text { Abstract / } \\
\text { Resumen }\end{array}$} & $\begin{array}{l}\text { The possibilities and didactic limitations of the computer games stand out. The utility of the } \\
\text { microcybergames in the educative surrounings of Internet is put of relief. In Java, the designs } \\
\text { of the microcybergames are studied, emphasizing the advantages of predesigned applet over } \\
\text { the ones generated by some author created tools. A selection of flexible and gratuitous applet } \\
\text { with possible didactic use is made. Examples of applications of these applets in proper contents } \\
\text { of Social Sciences in the no university curricula are incorporated. }\end{array}$ \\
\hline & $\begin{array}{l}\text { Se destacan las posibilidades y limitaciones didácticas de los juegos de ordenador. Se pone } \\
\text { de relieve la utilidad de los microciberjuegos en el entorno educativo de Internet. Se estudian } \\
\text { los diseñados en java, resaltándose las ventajas de applets prediseñados sobre los generados por } \\
\text { algunas herramientas de autor. Se realiza una selección de applets flexibles y gratuitos con } \\
\text { posible utilización didáctica. Se incorporan ejemplos de aplicación de estos applets en conte- } \\
\text { nidos propios de las Ciencias Sociales en los currículos no universitarios. }\end{array}$ \\
\hline \multirow{2}{*}{$\begin{array}{l}\text { Keywords } \\
\text { Descriptores }\end{array}$} & $\begin{array}{l}\text { Java; Internet; microcybergames; Applet; Social Sciences; Educational Games; Computer } \\
\text { Games; Learning Activities. }\end{array}$ \\
\hline & $\begin{array}{l}\text { Java; Internet; Microciberjuegos; Applet; Ciencias Sociales; Juegos Educativos; Juegos de Or- } \\
\text { denador; Actividades de Aprendizaje }\end{array}$ \\
\hline $\begin{array}{l}\text { Institution / } \\
\text { Institución }\end{array}$ & Instituto de Educación Secundaria $\mathrm{N}^{\circ} 1$ "Universidad Laboral” de Málaga (España) \\
\hline $\begin{array}{l}\text { Publication site / } \\
\text { Dirección }\end{array}$ & http://www.uv.es/RELIEVE \\
\hline $\begin{array}{l}\text { Language / } \\
\text { Idioma }\end{array}$ & Español (Title, abstract and keywords in english) \\
\hline
\end{tabular}

\section{Revista ELectrónica de Investigación y $\mathbf{E V}$ aluación $\mathbf{E}$ ducativa (RELIEVE)}

Electronic Journal of Educational Research, Assessment and Evaluation

[ ISSN: 1134-4032 ]

(C) Copyright, RELIEVE. Reproduction and distribution of this articles it is authorized if the content is no modified and their origin is indicated (RELIEVE Journal, volume, number and electronic address of the document).

(C) Copyright, RELIEVE. Se autoriza la reproducción y distribución de este artículo siempre que no se modifique el contenido y se indique su origen (RELIEVE, volumen, número y dirección electrónica del documento). 